\title{
LESSONS LEARNED FROM IPCC AR4 Scientific Developments Needed To Understand, Predict, And Respond To Climate Change
}

by Sarah J. Doherty, Stephan Bojinski, Ann Henderson-Sellers, Kevin Noone, David Goodrich, Nathaniel L. Bindoff, John A. Church, Kathy A. Hibbard, Thomas R. Karl, lucka Kajfez-Bogataj, Amanda H. lynch, David E. Parker, I. Colin Prentice, Venkatachalam Ramaswamy, Roger W. Saunders, Mark Stafford Smith, Konrad Steffen, Thomas F. Stocker, Peter W. Thorne, Kevin E. Trenberth,

Michel M. Verstraete, and Francis W. Zwiers

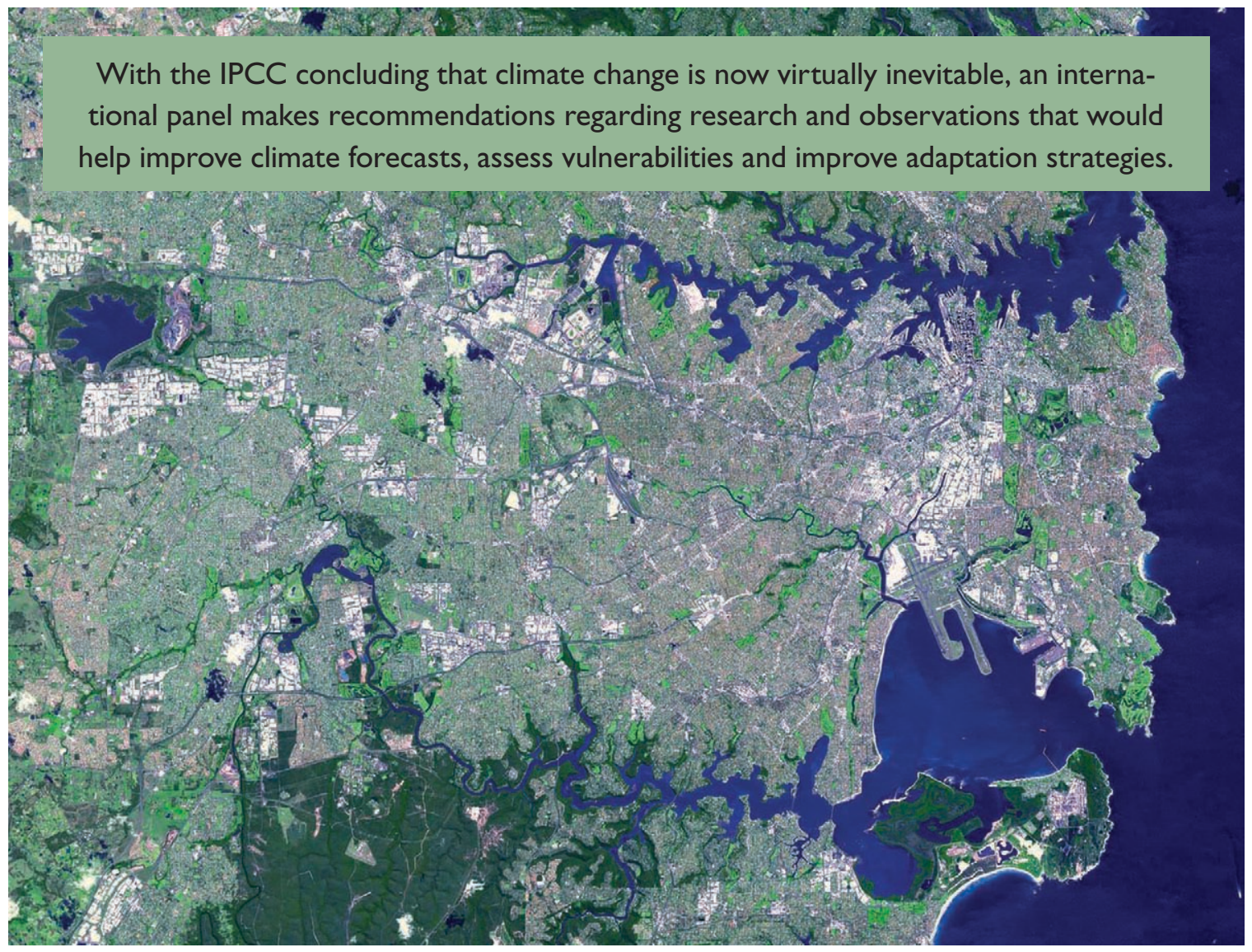

This view-from-above of Sydney, Australia exemplifies the close interaction between man and his environment and reminds us of the local scales over which climate change will affect human, natural, and economic systems. These relationships and how they should drive future research were discussed during a workshop held in Sydney in October, 2007. (Image courtesy of NASA/GSFC/METI/ERSDAC/JAROS, and U.S./Japan ASTER Science Team)
7 he periodic assessments of the Intergovernmental Panel on Climate Change (IPCC) of the causes, impacts, and possible response strategies to climate change are the most comprehensive and up-to-date reports available on the subject and form the standard reference for all concerned with climate change in academia, government, and industry worldwide. Hundreds of international experts contributed to the IPCC's Fourth Assessment Report (AR4), which has received unprecedented attention and acclaim by policy makers, scientists, industry, and the general public. 
The observations and research coordinated by the Global Climate Observing System (GCOS) program, the World Climate Research Programme (WCRP), and the International Geosphere-Biosphere Programme (IGBP) have been central to underpinning the assessments of the IPCC Working Groups I and II (WG I and II) to date (Solomon and Manning 2008). The working plans of GCOS, WCRP, and IGBP already contain substantial strategic guidance for future climate research and climate observations, which will contribute to future IPCC assessments. Actions to secure the necessary climate record and move toward a comprehensive global observing system for climate have been defined in the GCOS Implementation Plan (GCOS 2004); research for physical components of the climate system and for climate analysis, modeling, and attribution are guided by the WCRP Strategic Framework (WCRP 2005); and research needs regarding the interactions among biological, chemical, and physical processes and interactions with human systems and their modeling are described in the IGBP Science Plan and Implementation Strategy (IGBP 2006).

WCRP, GCOS, and IGBP recognized that these plans could be further strengthened by reviewing lessons learned in IPCC's AR4. As a result, recommendations were sought about key gaps and uncertainties in research and observations that hinder our ability to detect, describe, understand, forecast, and adapt to human-induced climate change. This was achieved through a survey sent to all IPCC AR4 WG I and II coordinating lead authors and other IPCC authors and experts, a workshop (October 2007; Sydney, Australia), and post-workshop exchanges. This process produced an extensive, although not exhaustive, set of recommendations (http://wcrp. wmo.int/documents/SydneyWorkshopRep_FINAL. pdf) that reflect the science fields covered by workshop participants.

Two fundamental classes of recommendations emerged from this process as follows:

\section{1) Improved process-level understanding, climate models, observations of climate-relevant pa- rameters and climate monitoring systems are needed in specific areas. \\ 2) Because some degree of climate change is vir- tually certain (IPCC 2007a), additional efforts are needed to make climate information more relevant to decisions concerning impacts, adap- tation and mitigation.}

In this paper, we address the research and observational strategies that lie at the intersection of these two bodies of recommendations-that is, those specifically aimed at improving the ability to predict and understand climate change impacts, adaptive capacity, and societal and ecosystem vulnerabilities.

Since the October 2007 workshop there have been a number of positive developments in this area. First, many of the detailed modeling needs identified in the workshop were addressed at the World Modeling Summit for Climate Prediction (6-9 May
AFFILIATIONS: DOHERTY—IGAC Core Project Office, NOAA-PMEL, Seattle, Washington; BoJINSKI AND GOODRICHGlobal Climate Observing System, WMO, Geneva, Switzerland; Henderson-Sellers-Climate Change Risk Research, Macquarie University, Sydney, New South Wales, Australia; NooneInternational Geosphere-Biosphere Programme, Royal Swedish Academy of Sciences, Stockholm, Sweden; BINDOFF-ACE CRC and CSIRO Marine Research, University of Tasmania, Hobart, Tasmania, Australia; $\mathrm{CHURCH}-$ Centre for Australian Weather and Climate Research and Antarctic Climate and Ecosystems, Cooperative Research Centre, Hobart, Tasmania, Australia; HiBBARD-NCAR,* Climate and Global Dynamics Division, Boulder, Colorado; KARL-NOAA/NCDC, Asheville, North Carolina; KAJFEZ-BogATAJ—University of Ljubljana, Ljubljana, Slovenia; LYNCH-Climate Program, Monash University, Victoria, Australia; Parker and Thorne-Met Office Hadley Centre, Exeter, United Kingdom; PrENTICE-QUEST, Department of Earth Sciences, University of Bristol, Bristol, United Kingdom; RAMASWAMY - NOAA/Geophysical Fluid Dynamics Laboratory, Princeton, New Jersey; SAUNDERS-Met Office Satellite Applications, Exeter, United Kingdom; STAFFORD SMITH-CSIRO Climate
Adaptation Flagship, CSIRO Sustainable Ecosystems and Desert Knowledge, CRC, Canberra, Australia; StefFen-University of Colorado, CIRES, Boulder, Colorado; STOCKER-Climate and Environmental Physics, Physics Institute, University of Bern, Bern, Switzerland; TRENBERTH-Climate Analysis Section, NCAR, Boulder, Colorado; VERSTRAETE-Institute for Environment and Sustainability, DG-Joint Research Centre, European Commission, Ispra, Italy; ZWIERs-Climate Research Division, Environment Canada, Downsview, Ontario, Canada

*The National Center for Atmospheric Research is sponsored by the National Science Foundation.

CORRESPONDING AUTHOR: Sarah J. Doherty, IGAC Core Project Office, NOAA-PMEL, 7600 Sand Point Way NE, Seattle, WA 98115

E-mail: igac.seattle@noaa.gov

The abstract for this article can be found in this issue, following the table of contents.

DOI: $10.1175 / 2008$ BAMS2643.1

In final form 7 November 2008

(C2009 American Meteorological Society 
2008), organized to develop a strategy to revolutionize prediction of the climate through the twenty-first century and in particular to help address the threat of global climate change at the regional level. The outcome was the recommendation of a "Climate Prediction Project” (see http://wcrp.ipsl.jussieu. fr/Workshops/ModelingSummit/Documents/ FinalSummitStat_6_6.pdf). Second, emissions scenarios for the Fifth Assessment Report (AR5) are now being developed in a coordinated fashion among the climate and Impacts, Adaptation, and Mitigation (IAM) communities, with "new scenarios" that will allow a previously missing consistency across the analyses of the three IPCC Working Groups. Further collaborations between the climate and impacts and vulnerability communities have also taken place in other forums: ESSP, ${ }^{1}$ its parent programs, the regional intergovernmental research networks Asian Pacific Network (APN) and Inter-American Institute (IAI), and the IPCC met with the parties to the United Nations Framework Convention on Climate Change (UNFCCC) at UNFCCC-SBSTA ${ }^{2} 28$ in Bonn, Germany, on 5 June 2008, with one focus of discussions being the need to augment process-level climate research by more direct coupling to adaptation and mitigation options, costs, and links with sustainable development. The recommendations made here contributed to and are built on these efforts.

\section{UNDERSTANDING AND PREDICTING CLIMATE CHANGE FOR ADAPTATION.}

It is very likely that most of the observed increase in global average temperatures since the mid-twentieth century is due to the observed increase in anthropogenic greenhouse gas concentrations and it is likely that there has been significant anthropogenic warming over the past 50 years averaged over every continent except the Antarctic (Solomon et al. 2007). Discernible human influences now extend to other aspects of climate, including ocean warming, continental-average temperatures, temperature extremes, wind patterns, and sea level rise during the latter half of the twentieth century (Solomon et al. 2007). There is also evidence that biophysical systems have been affected (Parry et al. 2007). However, our ability to interpret change in most other impact-relevant variables, such as changes in circulation, precipitation,

\footnotetext{
${ }^{1}$ This is the Earth System Science Partnership of WCRP, IGBP, DIVERSITAS, and IHDP, the International Human Dimensions Programme.

${ }^{2}$ This is the subsidiary Body for Scientific and Technological Advice to the UNFCCC.
}

and extremes of various types, remains more limited. To address these deficiencies we recommend:

Key research need \#I. Efforts are needed to improve the ability of models to reproduce fundamental aspects of the climate system, such as circulation and precipitation patterns, El Niño, and seasonal variability, as well as to reproduce other impact-relevant variables such as extremes in temperature and precipitation.

Models must be tested against observations, using established metrics to better understand persistent biases in model products. It will be important to communicate this understanding to users of climate information, including the general public. Several modeling activities aimed at resolving these issues-including modes of variability, $1-\mathrm{km}$ scales for convection, and high-impact weather (described by Trenberth 2008)-were addressed at the World Modeling Summit for Climate Prediction. These should be pursued.

Global average surface temperatures are projected to continue to increase over the next two decades at a rate of $\sim 0.2^{\circ} \mathrm{C}$ decade $^{-1}$ (Meehl et al. 2007), with accompanying changes in climate patterns that impact human and economic systems (Pachauri and Reisinger 2007). Climate science therefore must aim specifically to assist adaptation decisions around both the adverse and beneficial impacts of climate change. The main focus of the IPCC assessments has been on century and longer predictions of climate changes. These remain essential, but a parallel effort to decipher likely changes on a decadal time scale would be instrumental to support policy making. Such a concerted effort was proposed by Hibbard et al. (2007) for AR5 and is complementary to recommendations made by the Climate Prediction Project described above.

Key research need \#2. For decision-making, society requires climate forecasts on a 10-30-yr time scale, including quantification of uncertainties.

To be useful for decision making, decadal predictions must be accompanied by estimates of uncertainty via model ensemble runs that span uncertainties in - at a minimum-initial conditions, model parameterizations, and biophysical feedbacks. They must also be accompanied by regular evaluation of model predictions against observational data with biases identified and accounted for. Such predictions will result in probability distributions for fields of 
interest, such as "number of consecutive days with precipitation $<x \mathrm{~mm}$ day ${ }^{-1}$." The results of these predictions and their uncertainties must be presented in language that is both familiar and meaningful to policy makers (e.g. "1-in-100-year events" becoming "1-in-20-year events"). Such near-term projections would have direct use in the context of impacts and adaptation on the space-time scales of predictability, for example, for living marine resources, ice sheets, droughts, sea level, and meridional overturning circulation of the ocean (e.g., see Keenlyside et al. 2008; Smith et al. 2008). These decadal predictions should be initialized with observational data (e.g., Giannini et al. 2003; Schubert et al. 2004; Seager et al. 2005; Hurrell et al. 2004). However, because a climate model likely has differences from the real world, initialization with observations causes a "shock" to the system and a "spinup" period is required, followed by drift in the simulated climate to the model climate (Hibbard et al. 2007). Reducing these effects and dealing with them are vital areas for future research and these efforts should be supported.

In the 30-yr time frame, global climate projections are simplified by being only weakly sensitive to different emissions scenarios for long-lived greenhouse gases (Solomon et al. 2007, Fig. SPM.5). However, the necessary incorporation of observations and analyses into global gridded fields for model initialization is a major challenge owing to inadequate representation of physical processes, model biases, and incomplete observations (e.g., Trenberth 2008). A further issue is that impact-relevant information must be provided at the appropriate scale because decisions are by nature made on a local to regional basis. The coarse grid spacing of global climate models does not resolve many of the features critical to, for example, water resource management (such as small-scale variations in precipitation in mountainous regions; e.g., Jones et al. 2004), nor does it properly resolve extreme events (e.g., thunderstorms and tornadoes). Many physical and biogeochemical processes occurring in the atmosphere (e.g., in clouds) or at the land surface (e.g., exchanges of heat, moisture, and carbon with the atmosphere) also occur at spatial scales much finer than those explicitly represented in climate models. Further research and development efforts should be focused on improving regional climate information, for instance, through finer resolution, downscaling of models, and parameterizations of subgrid-scale processes.

Key research need \#3. In addition to the focus on global, decadal predictions, there should be increased focus on regional-scale climate information, accounting for land surface processes and biosphere-atmosphere interactions.

A critical question is how to produce credible regional information while correctly recognizing and communicating associated uncertainties. Here, credibility implies confidence in the model output on spatial scales commensurate with the needs of policy makers. Key questions include: When is a model good enough for providing policy-relevant information? In a given context, how do we define "good enough"? Does this vary across contexts?

The land surface is where humans and natural systems most often interact so there is a particular need for monitoring, analyzing, and predicting terrestrial processes at the regional scale (e.g., Henderson-Sellers et al. 2004). Natural ecosystems, agriculture, and forestry have been studied extensively in recent years, but we need to address the relative dearth of information on urban systems. Urban areas represent a rapidly growing sector of human and environmental interactions, with more than $50 \%$ of the world's population now living in cities. These areas are important both because very localized changes in climate can impact large populations and because the emissions and land use changes associated with urban areas can have significant impacts on biotic systems and climate at the local to global scale. More generally, drivers and impacts of anthropogenic land use and land cover change need to be better understood and represented in models.

Dynamical or statistical downscaling from global models should be used to generate high-resolution climate change information for attribution of past change, for understanding the processes that lead to change, and for projecting future change. Results in this area could be more effectively delivered by implementing programs that focus on well-defined regions based on policy decision regimes and that integrate across resource issues rather than across scientific disciplinary boundaries.

It is clear (Bader et al. 2008) that ocean-atmosphere global climate models (OAGCMs) have too coarse a resolution to resolve important features such as terrain effects on precipitation and coastal boundaries. To optimize regional predictability, a coordinated approach with regional climate models (RCMs) and higher-resolution global models is required. Given that multimodel ensembles have shown great value, RCM downscaling must be linked to a representative set of model simulations, rather than to just one or two OAGCMs. Also, accurate surface boundary 
conditions within the domain of both the regional and the global host models are required to reduce sensitivity arising from dependence on surface states (Zhang et al. 2001).

The statistical downscaling of models depends fundamentally on high-quality, high-resolution, and comprehensive observations to inform statistical approaches and to confirm error reductions in models. In addition, appropriate and robust statistical methods are needed for extremes, extrapolation, and downscaling, and these methods will need to be suitable for providing information useful to decision makers. Large ensemble model runs are required to model not only the central tendencies but also the occurrence of extreme events, some of which (like heat waves) can be explicitly resolved. Care is needed to ensure that statistical samples of regional models are long enough to be reliable for trend analysis. Because other finer-scale events of general importance, such as flash floods and tornadoes, cannot realistically be resolved, the modeling effort must be supported with careful statistical analysis of the relationship between model-scale features and extreme events.

Integral to this effort will be building a climate information system that provides the observations needed to understand fundamental physical aspects of the climate system, to attribute climate changes to specific causes, to account for impacts and adaptive response, and to deliver quality-controlled projections and predictions.

ENSURING THE OBSERVATIONAL RECORD FOR CLIMATE. An integrated set of global, atmospheric, oceanic, and terrestrial observing systems for climate monitoring, model validation, and climate model initialization is the foundation for all climate studies (GCOS 2004). It is critical that we commit to sustaining these observations, many of which are currently at risk. Both for ground-based and space-based observing systems, continuity of record is essential and contingency plans for gaps in the climate record must be developed to cover, for example, instrument failures. Beyond this, the observational records should be expanded and enhanced to underpin studies of climate change and its impacts, guided by the GCOS Implementation Plan (GCOS 2004).

Key research need \#4. Climate and impactrelevant observational data records should be I) reprocessed (as needed) to reflect new knowledge and to improve the flagging of errors and estimation of biases and 2) incorporated into reanalysis efforts and thus made available as global, gridded fields.

Multidecadal observational datasets commonly show unresolved and sometimes clearly unphysical drifts and discontinuities, even following attempts at homogenization. These inconsistencies make it difficult to make unequivocal statements on climate trends and their causes or on the capabilities of models to reproduce past changes. Often, new knowledge is gained about datasets after their initial processing and release, and climatically relevant datasets should be reprocessed to reflect this new understanding with the goal of homogenization across similar datasets. Moreover, reanalysis of the observations into global gridded fields is essential (Trenberth et al. 2008). At all reprocessing stages, the data must be fully archived, allowing full transparency and enabling new techniques for homogenizing datasets. Space agencies and the World Meteorological Organization (WMO) are developing the Global Satellite Inter-Calibration System, are establishing a global network of Regional Specialized Satellite Centers for Climate Monitoring, and have adopted the GCOS climate monitoring principles (GCOS 2004). Regular monitoring and analysis of groundbased observations for climate (e.g., surface temperature and precipitation) and rescue and digitization of historical climate records is provided on a routine basis by meteorological and oceanographic services, as well as by space agencies and other providers of remote sensing products. The datasets resulting from these efforts are regularly used in climate change research recognized in AR4 (e.g., Vose et al. 2005; Smith and Reynolds 2005). However, there is no formal process in place to assess the adequacy of datasets in meeting climate requirements (e.g., for homogeneity). Through an open process a set of metrics, such as a maturity index, needs to be developed that would identify datasets that either meet or exceed climate requirements or that are inadequate or suspect.

Further, there is a clear need to encourage a standard for metadata archiving where this is lacking, to enforce such standards, and to promote homogenization of the basic data. This work is essential for reanalysis projects, including for radiosonde and surface data before the satellite era (Thorne et al. 2005; Simmons et al. 2004). In many countries, records have only been digitized since the 1950s or 1960s. Digitizing and quality controlling the earlier data is needed to extend datasets for impact studies, reanalyses, and the evaluation of trends (Jones and Moberg 2003). 
While the steps outlined above address needs associated with understanding the physical climate system, for policy makers it is important to understand whether and how observed climate change is affecting physical, ecological, and human systems. IPCC's WG II went some way toward making this connection but could not be conclusive, partly because of lack of data coverage on impact-relevant variables.

Key research need \#5. Datasets must be expanded to include observations of the impacts of climate change and to account for autonomous or planned adaptation. Observations of impacts should especially be made I) in regions that have been identified as being highly vulnerable and 2 ) in regions that represent both weak and strong adaptive capacity.

Specifically, datasets should be sought and analyzed for areas outside of Europe and North America and should include human activities and socioeconomic conditions. As depicted in Fig. 1, such observations and other input will provide information on how a changing climate and societal responses affect emissions, in turn informing how climate research and observations should be modified in the context of measuring and predicting vulnerabilities.

Key research need \#6. A systematic approach must be established specifically to monitor and assess vulnerability.

This will require focused analysis of long-term datasets in some specific large regions to evaluate the impacts of climate change on selected natural systems. Projects of this nature [such as the National Ecological Observatory Network (NEON) in the United States; www.neoninc.org] would help to facilitate improved understanding and detection of impacts on ecosystems, foster an understanding of which systems and areas are more vulnerable, and improve the evaluation of relevant impact models. In addition, it would help provide a wider range of response functions for Integrated Assessment Models, including scenarios under both unmitigated and mitigated climate change and accounting for understanding of thresholds in the climate system. The range of processes for which response functions are needed (e.g., number of species at risk, area of reef lost, number of people with water and food security issues, forest fire susceptibility) must be defined, as must a core set of international metrics related to "dangerous climate change." This will need to build on existing efforts, as discussed by, for example, Schellnhuber (2006). It will be impor-

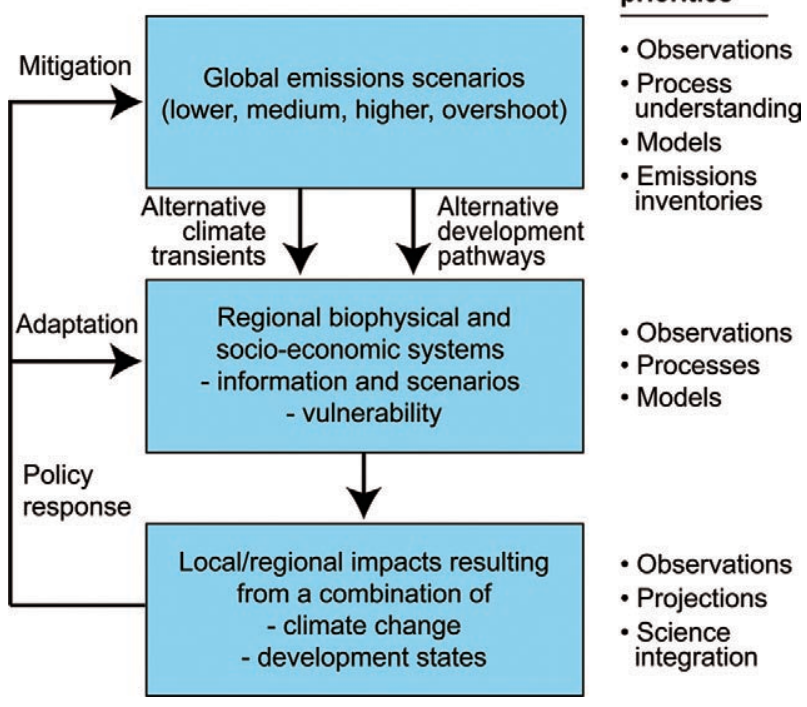

FIG. I. Society-relevant climate change issues (boxes); (right) high-priority science activities required to address these issues and (left) policy responses.

tant to understand whether regional responses can be generalized for extrapolation from regions with good data and knowledge to worldwide responses with regional resolution.

These goals hinge on the development of an issuebased definition of vulnerability: determining what would be the minimal datasets and variables required to detect change in, understand, and monitor vulnerable systems; mapping out the existing landscape of systematic monitoring systems beyond those currently encompassed by GCOS; and assessing what additional observations and mechanisms are needed. In parallel, adaptive capacity and adaptation must be studied as a starting point through a few well-studied case sectors selected from a broad range of geographic areas (e.g., coastal zones, Asian megadelta, subsistence farms, urban centers, small islands, drylands, and polar regions). Further clarity on the requirements for datasets and variables in connection to adaptation and vulnerability could be achieved through a series of targeted workshops involving climate researchers and representatives from important stakeholder communities (e.g., agriculture, water management and energy production) in different representative regions.

\section{HARMONIZATION ACROSS STUDIES ON CLIMATE, IMPACTS, ADAPTATION, AND VULNERABILITY. Currently, most climate change research uses as a starting point the development of emissions scenarios. These scenarios are then used in}


climate and other models to derive potential impacts. This should be complemented with an additional approach that starts by defining societal and ecosystem vulnerability and resilience (e.g., Elmqvist et al. 2003; Diffenbaugh et al. 2007) and then assesses what knowledge is required to forecast future impacts, as depicted in Fig. 2. This starting vision accounts for the fact that there are stresses other than climate change that must be considered when trying to understand vulnerabilities, which are a product of the sensitivity, anticipated exposure, and adaptive capacity of the system or region being impacted.

This framework of complementary approaches broadens the scope of the required data and process knowledge beyond that needed for long-term climate prediction to, for example, a wider variety of environmental and socio-economic variables. It will also require increased communication between impacts, adaptation, and vulnerability researchers and users. These communities are in the process of collaborating to define a limited set of key variables that would satisfy the capabilities and needs of researchers and users. Although there is not a single set of universal indicators, experience suggests that there is a limited set of variables-such as the 44 Essential Climate Variables (GCOS 2004) used for climate-that may provide a platform for risk assessment, adaptation, and resilience analyses. This collaborative list would significantly improve products from the impacts community that are used to inform decision making and policy, particularly with regard to clarifying local and regional information needs.

At the same time, changes are needed to the way emissions scenarios are formulated for the IPCC assessments. The IPCC Special Report on Emissions Scenarios (SRES) used for the Third and Fourth Assessments are based on a series of greenhouse gas emission storylines ("narratives") that make a range of assumptions about future energy consumption, technological innovations, land use allocations, and other human activities. These are used as input to Integrated Assessment Models (Nakicenovic and Smart 2000). This results in a strong quantitative approach that provides calculations of greenhouse gas concentrations and radiative forcings, allowing the climate modeling community to generate projections of global climate change. These fields are used to estimate impacts, which in turn are used to identify adaptation and resilience options and to assess their effectiveness. However, the tools used by the current impacts, adaptation, and vulnerability assessments are based on a variety of socioeconomic and environmental (including climatic) baselines

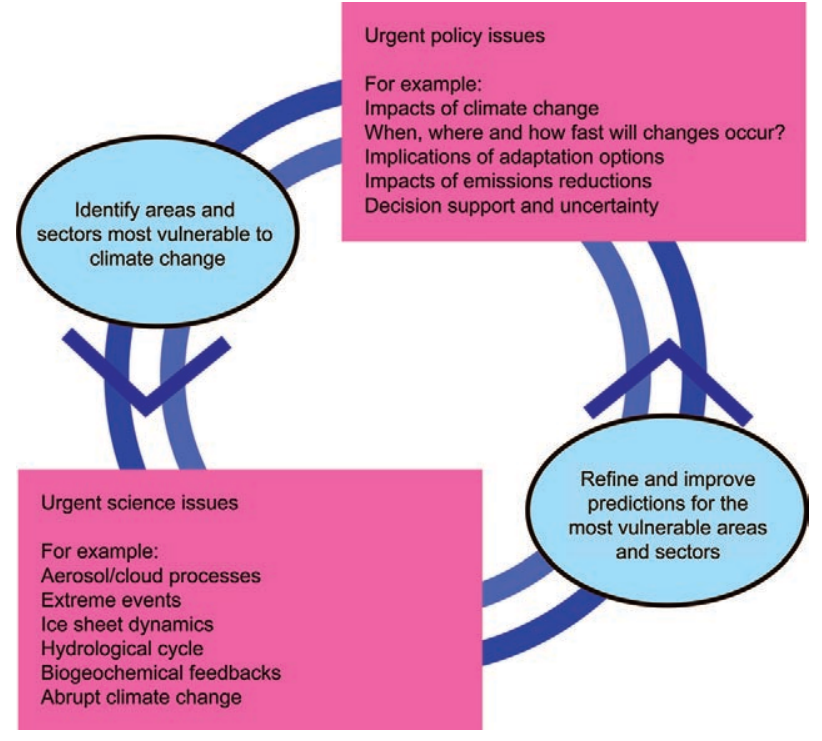

FIG. 2. Vulnerability should be used to link pressing science questions with societal concerns. A starting point is to define and identify areas of greatest vulnerability to climate change, to use this information to guide which science questions to address, and to obtain better model predictions and process understanding, which in turn helps inform and mitigate societal concerns and assessments of vulnerability.

combined with different scenario approaches that do not always utilize the full range of SRES scenarios (Carter et al. 2007). Additionally, assumptions made in various downscaling methodologies regarding the robustness of linear versus nonlinear processes (e.g., temperature versus precipitation) differ, as do the periods, regions, and spatial resolutions. This makes comparison among and across different analyses of impacts, adaptation, and vulnerability extremely difficult.

In light of this and in light of the recent changes in the earth's carbon cycle and our understanding of it (see next section), the communities that both develop and utilize SRES scenarios began a discussion two years ago to implement a strategy for both nextgeneration climate change experiments and the development of new scenarios (Hibbard et al. 2007; Moss et al. 2008). Climate and integrated assessment models are both becoming increasingly complex, with mutual implementation of the carbon cycle and other biogeochemical cycles and processes.

Key research need \#7. There is a need to develop and apply a consistent, harmonized set of scenarios of land use, land cover, and emissions databases to support both the climate and integrated assessment com- 
munities, with consistency across spatial and temporal scales, and considering both historic and future time scales.

Such an activity is currently in progress in support of developing representative concentration pathways (RCPs), which will be used by both the climate and integrated assessment communities toward the development of new scenarios (Moss et al. 2008). These RCPs are being designed to provide new baselines to account for rapid growth in, for example, China and India, which was not previously accounted for. Further, they will coordinate historic and future calculations. This harmonization activity will form the basis for the development of a new library of scenarios that will facilitate a parallel and much more integrative approach to understanding the physical and social implications and consequences of global change.

\section{KEY CLIMATE SCIENCE ISSUES IN THE CONTEXT OF IMPACTS. Although our un-} derstanding of the climate system and of climate changes improved considerably from the IPCC Third Assessment Report to AR4, critical gaps in aspects of climate science remain. These are discussed in detail in the AR4 Working Group I report. Here, we focus on deficiencies that should be resolved specifically because of their potentially profound impacts on society. While this clearly requires a good understanding of and ability to quantify the agents driving climate variations and change and an ability to forecast the mean climate state, it also emphasizes the importance of understanding the likelihood of high-risk, lowprobability events, many of which relate to nonlinear responses in the climate system.

Paleodata show that the climate has experienced abrupt changes in the past (Jansen et al. 2007; Overpeck and Cole 2006; Alley et al. 2003), where abrupt change is defined as a large-scale change in the climate system that takes place over a few decades or less, persists for at least a few decades, and causes substantial disruptions in human and natural systems. Two types of abrupt change that stand out in the paleoclimate record as being so rapid and drastic in their impact that their occurrence would pose a clear risk to society and that may occur in the next century are 1) widespread and sustained changes to the hydrologic cycle (Ely et al. 1993; Woodhouse and Overpeck 1998; Cook et al. 2004) and 2) rapid changes in glaciers and ice sheet mass and hence sea level (Fairbanks 1989; Alley et al. 2002; Siddall et al. 2003). In addition, the rapid rate of climate change that is forecast for the next century may produce significant, and possibly sudden, feedbacks in the global carbon cycle, which in turn could lead to rapid and sudden changes in the rate of climate change and its impacts. Finally, the impact of aerosols on cloud properties (the "indirect effect") is the largest source of uncertainty in constraining radiative forcing, with implications both for understanding past climate changes and for improving climate forecasts in the near term (next $\sim 30 \mathrm{yr}$ ), particularly in heavily polluted regions.

Changes to the hydrological cycle from anthropogenic climate change. Evidence of change in precipitation and the hydrologic cycle, including changes in extremes, is building (Trenberth et al. 2007), as is evidence that human-induced climate change is altering precipitation (Hegerl et al. 2007; Zhang et al. 2007; Min et al. 2008) and the hydrologic cycle (Barnett et al. 2008). Precipitation is obviously an important variable in terms of societal needs and environmental impacts; how it changes is critical for water management, agriculture, hydroelectric power, wildfire fighting, and many other applications.

Key research need \#8. Observations and novel technology should be utilized to better understand variations in the hydrologic cycle, both in the very short term and sustained over decades, in particular with respect to extremes.

New satellites (National Research Council 2007) and new technologies (such as stable isotope tracking; e.g., Henderson-Sellers et al. 2006) should be used to better understand the high-frequency component of the hydrologic cycle over land, soil moisture as the storage component of water over land (Jackson et al. 1995), and low-frequency supply-side component of the water balance over the oceans (Lagerloef et al. 1995).

Water supply predictions rely on the use of models, but both global and regional models have biases that lead to unrealistic features related to water supply, storage, and surplus (Sheffield and Wood 2007). Models tend to have precipitation that occurs too often, with insufficient intensity and with premature onset of precipitation, indicating fundamental problems in the physics of models, notably convective parameterizations (Randall et al. 2007; Trenberth et al. 2003). High-quality, high-resolution data are needed to evaluate these errors and confirm error reductions as models are improved. Full advantage needs to be taken of existing and planned measurements to quantify water fluxes to/from the land surface, atmosphere, and ocean. A deeper understanding of 
the coupling between the water and carbon cycles is also required because changes in water availability have a strong impact on vegetation and vice versa.

Natural and social systems tend to respond more to extreme events than to changes in the mean climate (Peterson et al. 2008), and ecosystems may respond irreversibly to extremes or when some threshold has been exceeded. By definition, extreme events represent the tails of the probability distributions, and so it is critical that probability distribution functions be based on a sufficient number of observations and that evaluation protocols for climate models take into account the statistics of extreme events. There is a particular need for higher-resolution, more precise data on the spatial and temporal character of precipitation, including type, frequency, intensity, and amount, both to improve our fundamental understanding of the hydrologic cycle and as a metric for testing models. An achievable goal would be to encourage and develop global hourly observations of precipitation at a horizontal resolution from $\sim 100$ (threshold) to $1 \mathrm{~km}$ (target) and encourage their use in evaluating models. With hourly data, analysis of the diurnal cycle, probability distributions, and extremes becomes straightforward.

New space-based observations of topsoil moisture [e.g., using the Advanced Microwave Scattering Radiometer for Earth Observing System (AMSR-E; www.ghcc.msfc.nasa.gov/AMSR/), Advanced Scatterometer (ASCAT), ${ }^{4}$ and Soil Moisture and Ocean Salinity (SMOS; online at www.esa.int/ esaLP/ESAMBA2VMOC_LPsmos_0.html) ${ }^{5}$ ] and full moisture content (including ground water from GRACE $^{6}$ ) and existing in situ soil moisture profile measurements will provide the opportunity to better understand the storage side of the water balance at the regional and global scales (Kerr et al. 2001; Njoku et al. 2003). New observations from global positioning system signals (surface and space-based), space based microwave observations, and existing in situ measurements of water vapor will allow us to better understand the changing character of precipitation. A concerted effort to optimally integrate the data from these different instruments needs to be undertaken. Space-based active radars and microwave measurements also provide new opportunities to resolve changes in precipitation over the surface ocean that

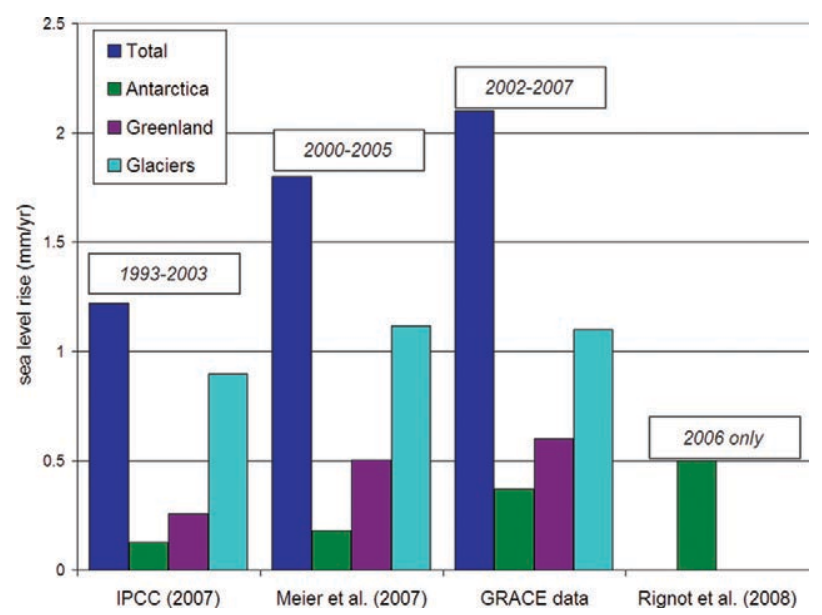

FIG. 3. Studies following closely after publication of the AR4 have resulted in significant increases in the estimated rate of sea level rise, with most of this increase coming from growing contributions by the Greenland and Antarctic ice sheets. Shown here are estimates of the cryospheric contribution to sea level rise as given in IPCC AR4 for the period 1993-2003 (Bindoff et al. 2007), as given by Meier et al. (2007) for 2000-05, and from the latest GRACE data for Apr 2002 through Oct 2007 (J. Wahr and I. Velicogna 2007, personal communication). Also shown is a recent estimate of the contribution to sea level rise of the Antarctic Ice Sheet for the year 2006 (Rignot et al. 2008).

can be cross-validated with changes in salinity from the Argo experiment (e.g., see www.argo.ucsd.edu). Surface salinity is now much better monitored (e.g., from SMOS, AQUARIUS; 7 online at http://aquarius. nasa.gov/), and new active and passive L-band radiometers promise additional surface salinity measurements. The IPCC AR4 noted that zonal changes in precipitation over the ocean could not be adequately resolved (Solomon et al. 2007, section 3.3.2.5), but it did illustrate the changing global-scale distributions of salinity through the world oceans (section 5.2.3). Deficiencies in existing datasets include potential instrumental biases, a need for greater robustness (e.g., more global analyses that balance the oceanic freshwater budget), a lack of deep-water salinities, and incomplete coverage of surface ocean salinity (e.g., in the Southern and South Pacific Oceans).

Ice sheet dynamics and sea level rise. Rising sea levels are a major emerging concern in the IPCC AR4, and

\footnotetext{
${ }^{4}$ This scatterometer is on board the EUMETSAT METOP satellite, launched in October 2006.

${ }^{5}$ SMOS is mission of the European Space Agency, due to be launched in 2009.

${ }^{6}$ GRACE is Gravity Recovery and Climate Experiment, with twin satellites launched in March 2002 to measure the Earth's gravity field.

${ }^{7}$ AQUARIUS is a NASA satellite mission to measure global sea surface salinity, which is planned for launch in 2010.
} 
more recent estimates indicate that sea level rise includes greater contributions from ice sheets than was given in AR4 (Fig. 3). These new observations also show that sea level is rising more rapidly than the AR4 central model projections, falling within the upper end of the projections (Rahmstorf et al. 2007) even when the uncertain contributions from land-based sources of ice are included (Fig. 3; Rignot et al. 2008; Meier et al. 2007; Bamber et al. 2007). As a result, there is concern that AR4 projections of future sea level rise may be significantly underestimated in models because the projections did not adequately include ice sheet processes thought to be responsible for the recent large contributions from Greenland and Antarctica.

There are uncertainties in all components contributing to present-day sea level rise: ocean thermal expansion for both the upper and deep ocean, contributions from glaciers and ice caps, potentially very large future contributions form the major ice sheets, and poorly constrained contributions from changes in terrestrial storage (Bindoff et al. 2007; Willis et al. 2008; Domingues et al. 2008). The greatest concern arises from rapidly growing contributions from the Greenland and West Antarctic ice sheets. Rapid changes are occurring in marginal regions of these ice sheets, with decreasing ice thickness and nearly twofold increases in flow rates closely following the reduction or loss of ice shelves induced by atmospheric or oceanic warming and increasing surface melting. This implies a causal connection between warming and ice sheet acceleration that is not currently represented in models (Rott et al. 2002; Scambos et al. 2004).

The interaction of warm waters with the periphery of the large ice sheets represents one of the most significant possibilities for abrupt change in the climate system. Mass loss through oceanic melting and iceberg calving accounts for more than $95 \%$ of the ablation from Antarctica and $40 \%-50 \%$ of that from Greenland (Rignot and Thomas 2002). Future changes in ocean circulation and ocean temperatures will produce changes in basal melting, but the magnitude of these changes is currently not adequately modeled or predicted. Emphasis should be given to supporting a new initiative to develop ice-sheet models that include these and other relevant physical processes, with a specific goal of representing the nonlinear response of ice sheets to climate change.

Key research need \#9. An immediate community initiative should be established that uses physical process studies, observations, and syntheses to obtain a consensus on the possible nonlinear responses of ice sheets to climate change, including their influences on rates of sea level rise.

Specific efforts should be undertaken to improve process-level understanding of the roles of ice shelf buttressing, ice thinning and floating, surface melting, water transport to the subglacier bed, heat transfer at the glacier-bedrock interface, and lubrication of subglacial channels, as well as interior ice, in modulating mass loss through outlet glaciers and ice streams.

A priority is to integrate estimates of the various contributions to sea-level rise, closing the sea-level budget (with observations and models) within realistic uncertainties, and using this information to refine projections. Measurements relevant to understanding sea level rise (e.g., satellite altimetry such as Jason ${ }^{8}$ and in situ observations from tide gauges fitted with GPS receivers) and ocean heat content should be maintained. Specifically, the Argo array needs to be maintained and extended into the ice-covered oceans and the deep and abyssal oceans using new technologies. Current difficulties with these observing systems (Willis et al. 2008) need to be resolved and overcome.

Carbon cycle feedbacks. The terrestrial and ocean environments are two key components of the Earth's carbon cycle. The oceans currently store $37 \%$ of carbon dioxide emissions (Denman et al. 2007) and there is concern that its capacity to store carbon is declining (Bindoff et al. 2007). Recent research, not available in time for AR4, suggests that the atmospheric concentration of $\mathrm{CO}_{2}$ is increasing at an accelerating rate because of an enhanced rate of burning of fossil fuels, cessation of the long-term trend of increasing carbon efficiency of economies, and the diminishing strength of the oceans' capacity to absorb carbon dioxide (Canadell et al. 2007a). As the climate changes, impacts on biotic systems will alter the capacity of terrestrial and oceanic systems to take up $\mathrm{CO}_{2}$, in turn affecting atmospheric concentrations. Currently these feedbacks are only partially understood and are either poorly represented in or completely absent from models (see, e.g., Field et al.

\footnotetext{
${ }^{8}$ The Jason satellites observe and monitor ocean dynamics (intraseasonal to interannual changes, mean sea level, tides) as a follow-on to the high-accuracy altimetry service provided since 1992 by TOPEX/Poseidon. Jason- 2 was launched on 20 June 2008.
} 
2007; Matsumoto 2007). Recent work also highlights the role of the nitrogen cycle in carbon feedbacks, which can change substantially as further processes are included (Thornton et al. 2007).

Key research need \#10. Efforts are needed to improve process modeling and understanding of feedbacks in the carbon cycle across the earth system. These will require I) a denser and more evenly distributed network of sustained in situ and remote sensing observations of carbon-related variables on land, in the oceans, and in the atmosphere, and 2) improvements to carbon-cycle models.

Carbon models currently disagree significantly with each other in uptake and emission rates and often do not match the available empirical evidence (Fig. 4; Friedlingstein et al. 2006; Jung et al. 2007, 2008). These uncertainties in the climate-carbon feedback (Fig. 4) correspond to an addition of between 20 and $224 \mathrm{ppm} \mathrm{CO}_{2}$ by 2100 relative to 1850 (Denman et al. 2007). In the ocean, critical processes include stratification (which influences the carbon uptake rate), large-scale changes in wind patterns, ocean warming, and acidification. The net effect of these factors on the ocean biological carbon pump is poorly known.

Atmospheric concentration measurements are currently too sparse to adequately constrain global- or regional-scale inversion models. Model improvements will require a better understanding of fundamental processes, both over land and in the ocean, notably 1) $\mathrm{CO}_{2}$ fertilization of terrestrial biota and its significance for the terrestrial carbon sink, 2) the observed decline in the efficiency of natural $\mathrm{CO}_{2}$ sinks (Canadell et al. 2007b; Le Quéré et al. 2007), 3) ocean acidification and its effect on the net carbon flux into seawater, and 4) the temperature response of net primary production (NPP), ecosystem carbon stocks, nitrogen cycling, soil decomposition, and soil moisture availability. Such advances will require a combination of field and modeling studies, as well as more comprehensive observations interpreted within a sound theoretical framework. Areas where significant rapid progress may be possible include the understanding and parameterization of the surface radiation and water balance and their impact on carbon cycle feedbacks and the uptake and release of carbon dioxide, over both continents and oceans.

Significant advances can also be expected through the generation of standardized remote sensing products (e.g., surface albedo, indicators of biological productivity, etc.) to characterize land and oceanic surfaces alike (Pinty et al. 2007; Gobron et al. 2007), as well as the effective assimilation of these products in climate and carbon models.

Components of a carbon flux observing system already exist in Europe (e.g., Geels et al. 2007), North America (e.g., Peters et al. 2007; Amiro et al. 2006), Asia (e.g., Yu et al. 2005, 2006), and East Asia and parts of the Atlantic and Pacific Oceans (Baldocci et al. 2001; Falge et al. 2002). Issues with

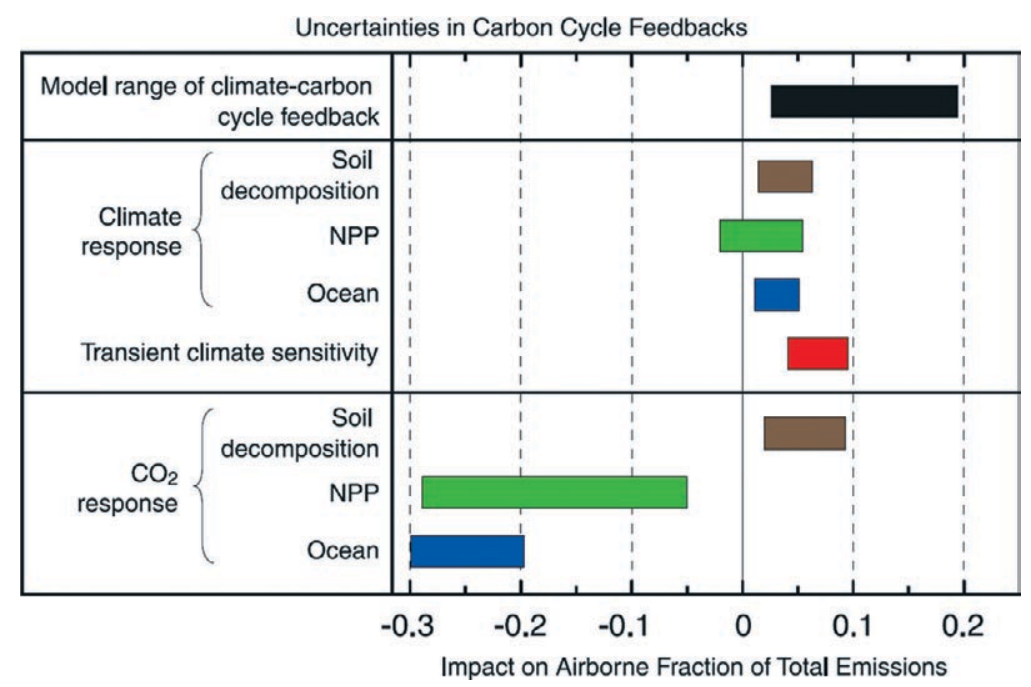

Fig. 4. Observations have been used to constrain the historic fraction of $\mathrm{CO}_{2}$ that is partitioned to the atmosphere at $238 \%-46 \%$ (Sabine et al. 2004). Climate-carbon cycle feedbacks impact this fraction, but in ways that are not yet fully understood. Estimates are based on C4MIP simulations using II models run from 1850 to 2100 under SRES scenario A2. The figure shows the multimodel mean changes in the airborne fraction for the year 2100 relative to the airborne fraction of that model without carbon cycle feedbacks. The net climate-carbon cycle feedback is estimated to be positive in all models, as evidenced by an increase in airborne fraction by the year 2100 in the range of 0.05 to 0.19 . The different carbon reservoirs respond differently to the physical climate changes (climate response) and the change in atmospheric and oceanic $\mathrm{CO}_{2}$ concentrations $\left(\mathrm{CO}_{2}\right.$ response). The uncertainties are due largely to processes on land (e.g., changes in soil decomposition and fertilization) and in the ocean (e.g., changes in uptake efficiency due to different circulation and stratification) associated with the $\mathrm{CO}_{2}$ response. (See Fig. 7.14 of IPCC WG I Report, chapter 7.) 
data continuity and consistency persist because these systems are largely based on short-term research efforts and are often operated without common measurement protocols, data management, and (for the land) complementary routine monitoring of field information about vegetation and soil properties. Continuation and expansion of measurements of $\mathrm{CO}_{2}$ concentrations and other carbon cycle tracers in the atmosphere is vital, as discussed in more detail in GCOS (2004).

Efforts should be pursued to evaluate and assimilate into the appropriate models other datasets relevant to biota involved in the carbon cycle-for example, land surface moisture flux, continentalscale runoff, and indicators of vegetative density and photosynthetic activity at both the land and ocean surfaces (e.g., Knorr et al. 2007). Care must be taken in the assimilation process (Pinty et al. 2006); remote sensing observations must be analyzed in terms of effective variables and their associated errors, which can then be consistently assimilated in models.

Aerosol and cloud forcing. A notable limitation in IPCC AR4 was that several of the climate models did not include representation of anthropogenic aerosol-cloud interactions (i.e. the "indirect" effect). Globally averaged, the net top-of-atmosphere mean radiative forcing by aerosols is estimated to be about $75 \%$ of that due to the $\mathrm{CO}_{2}$ increase since preindustrial times, but of opposite sign. About $60 \%$ of this negative forcing is via the "albedo effect" of aerosol-cloud interactions, which remains the most uncertain of the anthropogenic forcings owing to gaps in the knowledge of both aerosol and cloud processes (Forster et al. 2007). This uncertainty affects our ability to determine accurately the net anthropogenic radiative forcing since pre-industrial times and to robustly attribute the degree to which aerosols have influenced observed climate changes, particularly over the last half-century when their atmospheric concentrations are known to have increased. These uncertainties also affect quantification of the aerosol and net anthropogenic forcing in the near future, in turn leading to uncertainties in future temperature and hydrologic cycle trends. Large uncertainties in cloud-aerosol interactions are particularly profound in very polluted regions, where aerosol indirect effects may be comparable to or greater than greenhouse gas forcing. In addition, aerosol influences may have major implications for local and global climate if emissions of aerosols and their precursors are rapidly decreased (Brasseur and Roeckner 2005; Levy et al. 2008).
Key research need \#II. There is a critical need to improve understanding of the processes involved in aerosol indirect forcing (e.g., aerosol transport, convective processes, cloud formation and dissipation) and to represent them reliably in climate models. At a minimum, an upper bound on aerosol indirect effect radiative forcing both for the past and near future should be determined through a combination of model comparisons and measurements.

A principal challenge is the spatial, temporal, and chemical inhomogeneity of different species of aerosols, making it difficult to quantify their distributions, forcing, and impacts. A crucial test involves the comparisons of model-simulation variables against observations (e.g., aerosol and cloud microphysical properties on a range of space and time scales). Observational data available to understand relevant processes and evaluate model simulations have increased significantly in the past few years, including that from newly launched satellites (e.g., CALIPSO; online at www-calipso.larc.nasa.gov/), airborne field campaigns, ground-based stations, and ships.

In the wake of AR4, modeling centers have begun to include interactive aerosol chemistry schemes and thus aerosol-cloud interactions in climate models (e.g., Penner et al. 2006; Storelvmo et al. 2006; Hansen et al. 2007; Lohmann et al. 2007; Ming et al. 2007). The opportunity is ripe for systematically examining models that incorporate this effect through both model-model and model-observation comparisons of, for example, aerosol optical depth, cloud optical depth, cloud fraction, drop effective radius, and radiative fluxes at both the surface and the top of the atmosphere.

Because of the large number of variables that control cloud properties and the substantial variability from region to region in the relative importance of these controlling factors, a "best guess" value with reduced uncertainty for the total global radiative forcing due to aerosol-cloud interactions may remain elusive in the near term given the available resources. An alternative approach is to design a limited number of experiments to determine whether the very large indirect effect predicted by some models is conceivable. These experiments should be undertaken in areas where models predict a large aerosol indirect effect and should incorporate comprehensive observations of atmospheric thermodynamics, chemistry, and aerosol and cloud droplet properties.

In many respects, aerosols, like water vapor, represent a feedback in addition to a forcing variable 
owing to their short lifetimes and interactive nature with clouds. For some aerosols there is no defining threshold between "very hydrated aerosol" and "small cloud droplet” (e.g., Kulmala et al. 1997; Charlson et al. 2007). New datasets (e.g. CALIPSO/CloudSat) and high-resolution cloud models should be used to determine to what degree there is a continuum between hydrated aerosol and cloud droplets and how this continuum is affecting assessment of the indirect effect.

CONCLUSIONS. With the increased recognition that the Earth's climate is changing because of human activities comes a growing demand by decision makers for reliable, quantitative climate information appropriate for use in assessments of climate change, adaptation, impacts, and vulnerability. Here we make recommendations for improvements to models and observational systems that, if fully implemented, will yield substantial benefits to this end. These recommendations are based on a survey of all IPCC AR4 WG I and II coordinating lead authors and other experts and on a workshop and follow-on discussions among a subset of these individuals, who by definition reflect a targeted but comprehensive body of expertise.

At the most fundamental level, efforts are needed to improve model representation of impact-relevant climate patterns beyond single climate variables such as temperature trends. Climate science also needs to focus urgently on providing climate change information for the 10-30-yr time frame, including highquality, reliable regional information and predictions to complement the longer-term projections. Improvement in these areas will require better homogenization and reanalysis of climate and impact-relevant observations and strengthened long-term observing systems, as well as targeted, new observations of impacts, adaptive responses, and vulnerability. Four areas of fundamental climate research are also identified that have direct consequences for understanding and predicting impacts and therefore merit focused effort: changes in the hydrologic cycle (in particular extremes), the processes contributing to rapid changes in ice sheet dynamics and hence to sea level rise, the climate-carbon cycle and land surface processes and feedbacks, and aerosol-cloud interactions.

We recognize that many of the recommendations made above impose difficult challenges for models that still have problems reproducing important features such as El Niño and that produce unrealistic patterns, such as the tendency toward a double ITCZ (Randall et al. 2007). However, in addition to making fundamental improvements in global modeling, needs dictate that climate modelers move on to the more complex issues of studying and forecasting changes in a broad array of impact-relevant fields and extreme events at a regional scale. The near certainty that society will face significant climate change (with a best-guess warming of $0.2^{\circ} \mathrm{C}$ decade ${ }^{-1}$; Meehl et al. 2007) and the associated impacts in the coming decades imparts an urgency to rapidly cope with these challenges. Large uncertainties will undoubtedly be a feature of any such forecasts, but this should not be a deterrent to taking up the problems swiftly because time will be needed not only to generate the required model and observational improvements but also for the essential task of identifying the communication framework, statistical approaches, and metrics that will be both useful to end users and can be produced by the modeling and measurement community. If successful, advances in these areas will provide new and important evidence for any future IPCC assessments starting with the AR5, allow better harmonization across the three IPCC working groups, and, more broadly, better align with the questions of societal relevance that are now being asked with greater frequency and urgency.

ACKNOWLEDGEMENTS. The workshop held in Sydney, Australia, 4-6 October 2007, was sponsored by the following institutions: the Australian Department of Climate Change, Australian Research Council Research Network for Earth System Science, Bureau of Meteorology, CSIRO, GCOS, International Council for Science, Intergovernmental Oceanographic Commission, IGBP, IPCC, NASA, NOAA, New South Wales Government, Australian Universities Climate Consortium, UNEP, WCRP, and WMO. The authors would like to thank Paul Mason (University of Reading, United Kingdom) and Adrian J. Simmons (European Centre for MediumRange Weather Forecasts, Reading, United Kingdom) for their input to the manuscript. The Met Office Hadley Centre authors are supported by the Joint Defra and MoD Integrated Climate Programme-GA01101, CBC/2B/0417_ Annex C5. Australian university scientists acknowledge support from the Australian Research Council and the Australian Government's Cooperative Research Centres Programme through the Antarctic Climate and Ecosystems Cooperative Research Centre.

\section{REFERENCES}

Alley, R. B., and Coauthors, 2002: Abrupt Climate Change: Inevitable Surprises. National Academy Press, 244 pp. 
- - and Coauthors, 2003: Abrupt climate change. Science, 299, 2005-2010.

Amiro, B. D., and Coauthors, 2006: Carbon, energy and water fluxes at mature and disturbed forest sites, Saskatchewan, Canada. Agric. For. Meteor., 136, 237-251.

Bader, D. C., C. Covey, W. J. Gutowski, I. M. Held, K. E. Kunkel, R. L. Miller, R. T. Tokmakian, and M. H. Zhang, 2008: Climate models: An assessment of strengths and limitations. Synthesis and assessment product 3.1., U.S. Climate Change Science Program and the Subcommittee on Global Change Research Report, $124 \mathrm{pp}$. [Available online at www.climatescience. gov/Library/sap/sap3-1/final-report/default.htm.]

Baldocci, D., and Coauthors, 2001: Fluxnet: A new tool to study the temporal and spatial variability of ecosystem-scale carbon dioxide, water vapor, and energy flux densities. Bull. Amer. Meteor. Soc., 82, 2415-2434.

Bamber, J., R. B. Alley, and I. Joughin, 2007: Rapid response of modern day ice sheets to external forcing. Earth Planet. Sci. Lett., 257, 1-13.

Barnett, T. P., and Coauthors, 2008: Human-induced changes in the hydrology of the western United States. Science, 319, 1080-1083.

Bindoff, N. L., and Coauthors, 2007: Observations: Oceanic climate change and sea level. Climate Change 2007: The Physical Science Basis, S. Solomon et al., Eds., Cambridge University Press, 385-432.

Brasseur, G. P., and E. Roeckner, 2005: Impact of improved air quality on the future evolution of climate. Geophys. Res. Lett., 32, L23704, doi:10.1029/2005GL023902.

Canadell, J. G., and Coauthors, 2007a: Contributions to accelerating atmospheric $\mathrm{CO}_{2}$ growth from economic activity, carbon intensity, and efficiency of natural sinks. Proc. Nat. Acad. Sci. USA, 104, 18 866-18 870, doi:10.1073/pnas.0702737104.

—, D. Pataki, R. Gifford, R. A. Houghton, Y. Lou, M. R. Raupach, P. Smith, and W. Steffen, 2007b: Saturation of the terrestrial carbon sink. Terrestrial Ecosystems in a Changing World, J. G. Canadell, D. Pataki, and L. Pitelka, Eds., IGBP Series, SpringerVerlag, 59-78.

Carter, T. R., and Coauthors, 2007: New assessment methods and the characterisation of future conditions. Climate Change 2007: Impacts, Adaptation, and Vulnerability, M. L. Parry et al., Eds., Cambridge University Press, 133-171.

Charlson, R. J., A. S. Ackerman, F. A.-M. Bender, T. L. Anderson, and Z. Liu, 2007: On the climate forcing consequences of the albedo continuum between cloudy and clear air. Tellus, 59, 715-727.
Cook, E., C. A. Woodhouse, C. M. Eakin, D. M. Meko, and D. W. Stahle, 2004: Long-term aridity changes in the western United States. Science, 306, 1015-1018.

Denman, K. L., and Coauthors, 2007: Couplings between changes in the climate system and biogeochemistry. Climate Change 2007: The Physical Science Basis, S. Solomon et al., Eds., Cambridge University Press, 499-587.

Diffenbaugh, N. S., F. Giorgi, L. Raymond, and B. Xunqiang, 2007: Indicators of 21st century socioclimatic exposure. Proc. Natl. Acad. Sci. USA, 104, 20 195-20 198, doi:10.1073/pnas.0706680105.

Domingues, C. M., J. A. Church, N. J. White, P. J. Gleckler, S. E. Wijffels, P. M. Barker, and J. R. Dunn, 2008: Improved estimates of upper ocean warming and multi-decadal sea level rise. Nature, 453, 1090-1093.

Elmqvist, T., C. Folke, M. Nyström, G. Peterson, J. Bengtsson, B. Walker, and J. Norberg, 2003: Response diversity, ecosystem change, and resilience. Frontiers Ecol. Environ., 1, 488-494.

Ely, L. L., Y. Enzel, V. R. Baker, and D. R. Cayan, 1993: A 5000-year record of extreme floods and climate change in the southwestern United States. Science, 262, 410-412.

Fairbanks, R. G., 1989: A 17 000-year glacio-eustatic sea level record: Influence of glacial melting rates on the Younger Dryas event and deep ocean circulation. Nature, 342, 637-642.

Falge, E., and Coauthors, 2002: Phase and amplitude of ecosystem carbon release and uptake potentials as derived from FLUXNET measurements. Agric. For. Meteor., 114, 75-95.

Field, C. B., D. B. Lobell, H. A. Peters, and N. R. Chiariello, 2007: Feedbacks of terrestrial ecosystems to climate change. Annu. Rev. Environ. Res., 32, 1-29.

Forster, P., and Coauthors, 2007: Changes in atmospheric constituents and in radiative forcing. Climate Change 2007: The Physical Science Basis, S. Solomon et al., Eds., Cambridge University Press, 129-234.

Friedlingstein, P., and Coauthors, 2006: Climatecarbon cycle feedback analysis: Results from the $\mathrm{C}^{4} \mathrm{MIP}$ model intercomparison. J. Climate, 19, 3337-3353.

GCOS, 2004: Implementation plan for the Global Observing System for Climate in support of the UNFCCC. GCOS-92, WMO/TD-No 1219. [Available online at www.wmo.int/pages/prog/gcos/ Publications/gcos-92_GIP.pdf.]

Geels, C. M., and Coauthors, 2007: Comparing atmospheric transport models for future regional inversions over Europe. Part 1: Mapping the atmospheric $\mathrm{CO}_{2}$ signals. Atmos. Chem. Phys., 7, 3461-3479. 
Giannini, A., R. Saravanan, and P. Chang, 2003: Oceanic forcing of Sahel rainfall on interannual to interdecadal time scales. Science, 302, 1027-1030.

Gobron, N., B. Pinty, F. Mélin, M. Taberner, M. M. Verstraete, M. Robustelli, and J.-L. Widlowski, 2007: Evaluation of the MERIS/ENVISAT FAPAR product. Adv. Space Res., 39, 105-115.

Hansen, J., and Coauthors, 2007: Climate simulations for 1880-2003 with GISS modelE. Climate Dyn., 29, 661-696.

Hegerl, G. C., and Coauthors, 2007: Understanding and attributing climate change. Climate Change 2007: The Physical Science Basis, S. Solomon et al., Eds., Cambridge University Press, 663-745.

Henderson-Sellers, A., K. McGuffie, D. Noone, and P. Irannejad, 2004: Using stable water isotopes to evaluate basin-scale simulations of surface water budgets. J. Hydrometeor., 5, 805-822.

— lation by current land-surface schemes: Results of iPILPS Phase 1. Global Planet. Change, 51, 34-58.

Hibbard, K. A., G. Meehl, P. Cox, and P. Friedlingstein, 2007: A strategy for climate change stabilization experiments. Eos, Trans. Amer. Geophys. Union, 88, doi:10.1029/2007EO200002.

Hurrell, J. W., M. P. Hoerling, A. S. Phillips, and T. Xu, 2004: Twentieth century North Atlantic climate change. Part I: Assessing determinism. Climate Dyn., 23, 371-389.

IGBP, 2006: IGBP Science Plan and Implementation Strategy. IGBP Rep. 55. [Available online at www. igbp.net/page.php?pid=222.]

Jackson, T. J., D. M. Le Vine, C. T. Swift, T. J. Schmugge, and F. R. Schiebe, 1995: Large area mapping of soil moisture using the ESTAR passive microwave radiometer in Washita '92. Remote Sens. Environ., 53, 27-37.

Jansen, E., and Coauthors, 2007: Palaeoclimate. Climate Change 2007: The Physical Science Basis, S. Solomon et al., Eds., Cambridge University Press, 433-497.

Jones, P. D., and A. Moberg, 2003: Hemispheric and large-scale surface air temperature variations: An extensive revision and update to 2001. J. Climate, 16, 206-223.

Jones, R. G., M. Noguer, D. C. Hassell, D. Hudson, S. S. Wilson, G. J. Jenkins, and J. F. B. Mitchell, 2004: Generating high-resolution climate change scenarios using PRECIS. Met Office, 40 pp.

Jung, M., and Coauthors, 2007: Uncertainties of modeling gross primary productivity over Europe: A systematic study on the effects of using different drivers and terrestrial biosphere models. Global Biogeochem. Cycles, 21, GB4021, doi:10.1029/2006GB002915.
—, M. M. Verstraete, N. Gobron, M. Reichstein, D. Papale, A. Bondeau, M. Robustelli, and B. Pinty, 2008: Diagnostic assessment of European gross primary production. Global Change Biol., 14, doi:10.1111/j.1365-2486.2008.01647.x.

Keenlyside, N. S., M. Latif, J. Jungclaus, L. Kornblueh, and E. Roeckner, 2008: Advancing decadal-scale climate prediction in the North Atlantic sector. Nature, 453, 84-88.

Kerr, Y. H., P. Waldteufel, J.-P. Wigneron, J. Font, and M. Berger, 2001: Soil moisture retrieval from space: The Soil Moisture and Ocean Salinity (SMOS) mission. IEEE Trans. Geosci. Remote Sens., 29, 1729-1735.

Knorr, W., N. Gobron, M. Scholze, T. Kaminski, R. Schnur, and B. Pinty, 2007: Impact of terrestrial biosphere carbon exchanges on the anomalous CO2 increase in 2002-2003. Geophys. Res. Lett., 34, L09703, doi:10.1029/2006GL029019.

Kulmala, M., A. Laaksonen, R. J. Charlson, and P. Korhonen, 1997: Clouds without supersaturation. Nature, 388, 336-337.

Lagerloef, G. S. E., C. T. Swift, and D. M. Le Vine, 1995: Sea-surface salinity: The next remote sensing challenge. Oceanography, 8, 44-50.

Le Quéré, C., and Coauthors, 2007: Saturation of the Southern Ocean $\mathrm{CO}_{2}$ sink due to recent climate change. Science, 316, 1735-1738.

Levy, H., M. D. Schwarzkopf, L. Horowitz, V. Ramaswamy, and K. L. Findell, 2008: Strong sensitivity of late 21st century climate to projected changes in shortlived air pollutants. J. Geophys. Res., 113, D06102, doi:10.1029/2007JD009176.

Lohmann, U., and Coauthors, 2007: Cloud microphysics and aerosol indirect effects in the global climate model ECHAM5-HAM. Atmos. Chem Phys., 7, 3425-3446.

Matsumoto, K., 2007: Biology-mediated temperature control on atmospheric $\mathrm{pCO}_{2}$ and ocean biogeochemistry. Geophys. Res. Lett., 34, doi:10.1029/2007GL031301.

Meehl, G. A., and Coauthors, 2007: Global Climate Projections. Climate Change 2007: The Physical Science Basis, S. Solomon et al., Eds., Cambridge University Press, 747-845.

Meier, M., M. B. Dyurgerov, U. K. Rick, S. O’Neel, W. T. Pfeffer, R. S. Anderson, S. P. Anderson, and A. F. Glazovsky, 2007: Glaciers dominate eustatic sea-level rise in the 21st century. Science, 317, 1064-1067.

Min, S.-K., X. Zhang, F. W. Zwiers, 2008: Humaninduced Arctic moistening. Science, 320, 518-520.

Ming, Y., V. Ramaswamy, L. J. Donner, V. T. J. Phillips, S. A. Klein, P. A. Ginoux, and L. W. Horowitz, 2007: Modeling the interactions between aerosols and liquid water clouds with a self-consistent cloud 
scheme in a general circulation model. J. Atmos. Sci., 64, 1189-1209.

Moss, T., and Coauthors, 2008: Towards New Scenarios for Analysis of Emissions, Climate Change, Impacts, and Response Strategies. Intergovernmental Panel on Climate Change, Geneva, 132 pp. [Available online at www.ipcc.ch or www.aimes.ucar.edu.]

Nakicenovic, N., and R. Smart, Eds., 2000: Special Report on Emissions Scenarios. Cambridge University Press, 570 pp.

National Research Council, 2007: Earth Science and Applications from Space. National Academies Press, $456 \mathrm{pp}$.

Njoku, E. G., T. J. Jackson, V. Lakshmi, T. K. Chan, and S. V. Nghiem, 2003: Soil moisture retrieval from AMSR-E. IEEE Trans. Geosci. Remote Sens., 41, 215-229.

Overpeck, J. T., and J. E. Cole, 2006: Abrupt change in Earth's climate system. Annu. Rev. Environ. Resour., 31, 1-31, doi:10.1146/annurev.energy.30.050504. 144308.

Pachauri, K., and A. Reisinger, Eds., 2007: Climate Change 2007: Synthesis Report. IPCC, 104 pp.

Parry, M. L., O. F. Canziani, J. P. Palutikof, P. J. van der Linden and C. E. Hanson, Eds., 2007: Climate Change 2007: Impacts, Adaptation, and Vulnerability. Cambridge University Press, 939 pp.

Penner, J. E., and Coauthors, 2006: Model intercomparison of indirect aerosol effects. Atmos. Chem. Phys., 6, 3391-3405.

Peters, W., and Coauthors, 2007: An atmospheric perspective on North American carbon dioxide exchange: Carbon tracker. Proc. Natl. Acad. Sci. USA, 104, 18 925-18930.

Peterson, T. C., and Coauthors, 2008: Why weather and climate extremes matter. Climate Change Science Program Synthesis and Assessment Product 3.3. T. R. Karl et al. National Climatic Data Center, 11-33. [Available online at www.climatescience.gov/Library/ sap/sap3-3/final-report/default.htm.]

Pinty, B., T. Lavergne, R. E. Dickinson, J.-L. Widlowski, N. Gobron, and M. M. Verstraete, 2006: Simplifying the interaction of land surfaces with radiation for relating remote sensing products to climate models. J. Geophys. Res., 111, D02116, doi:10.1029/2005JD005952.

— , and Coauthors, 2007: Retrieving surface parameters for climate models from MODISMISR albedo products. J. Geophys. Res., 112, doi:10.1029/2006JD008105.

Randall, D. A., and Coauthors, 2007: Climate models and their evaluation. Climate Change 2007: The Physical Science Basis. S. Solomon et al., Eds., Cambridge University Press, 589-662.
Rignot, E., and R. Thomas, 2002: Mass balance of polar ice sheets. Science, 297, 1502-1506.

_, J. L. Bamber, M. R. van den Broeke, C. Davis, Y. H. Li, W. J. van de Berg, and E. van Meijgaard, 2008: Recent Antarctic ice mass loss from radar interferometry and regional climate modeling. Nature Geosci., 1, 106-110.

Rott, H., W. Rack, R. Skvarca, and H. de Angelis, 2002: Northern Larsen Ice Shelf, Antarctica: Further retreat after collapse. Ann. Glaciol., 34, 277-282.

Sabine, C. L., and Coauthors, 2004: The oceanic sink for anthropogenic $\mathrm{CO}_{2}$. Science, 305, 367-371.

Scambos, T., J. A. Bohlander, C. A. Shuman, and P. Skvarca, 2004: Glacier acceleration and thinning after ice shelf collapse in the Larsen B embayment, Antarctica. Geophys. Res. Lett., 31, doi:10.1029/2004GL020670.

Schellnhuber, H. J., 2006: Avoiding Dangerous Climate Change. Cambridge University Press, 406 pp.

Schubert, S. D., M. J. Suarez, P. J. Region, R. D. Koster, and J. T. Bacmeister, 2004: Causes of long-term drought in the United States Great Plains. J. Climate, 17, 485-503.

Seager, R., Y. Kushnir, C. Herweijer, N. Naik, and J. Velez, 2005: Modeling of tropical forcing of persistent droughts and pluvials over western North America: 1856-2000. J. Climate, 18, 4065-4088.

Sheffield, J., and E. F. Wood, 2007: Characteristics of global and regional drought, 1950-2000: Analysis of soil moisture data from an off-line simulation of the terrestrial hydrologic cycle. J. Geophys. Res., 109D, D24108, doi:10.1029/2006JD008288.

Siddall, M., E. J. Rohling, A. Amogi-Labin, C. Hemleben, D. Meischner, I. Schmelzer, and D. A. Smeed, 2003: Sea-level fluctuations during the last glacial cycle. Nature, 423, 853-858.

Simmons, A. J., and Coauthors, 2004: Comparison of trends and low-frequency variability in CRU, ERA-40, and NCEP/NCAR analyses of surface air temperature. J. Geophys. Res., 109, D24115, doi:10.1029/2004JD005306.

Smith, D. M., S. Cusack, A. W. Colman, C. K. Folland, G. R. Harris, J. M. Murphy, 2008: Improved surface temperature prediction for the coming decade from a global climate model. Science, 317, 796-799.

Smith, T. M., and R. W. Reynolds, 2005: A global merged land and sea surface temperature reconstruction based on historical observations (1880-1997). J. Climate, 18, 2021-2036.

Solomon, S., and M. Manning, 2008: The IPCC must maintain its rigor. Science, 319, 1457, doi:10.1126/ science. 1155724 . 
—, D. Qin, M. Manning, Z. Chen, M. Marquis, K. B. Avery, M. Tignor, and H. L. Miller, Eds., 2007: Climate Change 2007: The Physical Science Basis. Cambridge University Press, 996 pp.

Storelvmo, T., J. E. Kristjánsson, S. J. Ghan, A. Kirkevåg, $\varnothing$. Seland, and T. Iversen, 2006: Predicting cloud droplet number concentration in Community Atmosphere Model (CAM)-Oslo. J. Geophys. Res., 111, D24208, doi:10.1029/2005JD006300.

Thorne, P. W., D. E. Parker, S. F. B. Tett, P. D. Jones, M. McCarthy, H. Coleman, and P. Brohan, 2005: Revisiting radiosonde upper air temperatures from 1958 to 2002. J. Geophys. Res., 110, D18105, doi:10.1029/2004JD005753.

Thornton, P. E., J.-F. Lamarque, N. A. Rosenbloom, and N. M. Mahowald, 2007: Influence of carbon-nitrogen cycle coupling on land model response to $\mathrm{CO}_{2}$ fertilization and climate variability. Global Biogeochem. Cycles, 21, GB4018, doi:10.1029/2006GB002868.

Trenberth, K. E., 2008: Observational needs for climate prediction and adaptation. WMO Bull., 57, 15-21.

—, A. Dai, R. M. Rasmussen, and D. B. Parsons, 2003: The changing character of precipitation. Bull. Amer. Meteor. Soc., 84, 1205-1217.

— atmospheric climate change. Climate Change 2007: The Physical Science Basis, S. Solomon et al., Eds., Cambridge University Press, 235-336.

- T. Koike, and K. Onogi, 2008: Progress and prospects for reanalysis for weather and climate. Eos, Trans. Amer. Geophys. Union, 89, doi:10.1029/2008EO260002.
Vose, R. S., D. R. Easterling, and B. Gleason, 2005: Maximum and minimum temperature trends for the globe: An update through 2004. Geophys. Res. Lett., 32, L23822, doi:10.1029/2004GL024379.

WCRP, 2005: World Climate Research Programme Strategic Framework 2005-2015. WCRP-123. [Available online at http://wcrp.ipsl.jussieu.fr/Documents/ SF_COPESSept05.pdf.]

Willis, J. K., D. P. Chambers, and R. S. Nerem, 2008: Assessing the globally averaged sea level budget on seasonal to interannual timescales. J. Geophys. Res., 113, C06015, doi:10.1029/2007JC004517.

Woodhouse, C. A., and J. Overpeck, 1998: 2000 years of drought variability in the central United States. Bull. Amer. Meteor. Soc., 79, 2693-2714.

Yu, G. R., L. M. Zhang, X. M. Sun, Y. L. Fu, and Z. Q. Li, 2005: Advances in carbon flux observations and research in Asia. Sci. China, 48D (Suppl. 1), 1-16.

$\longrightarrow$, X. F. Wen, X. M. Sun, B. D. Tanner, X. H. Lee, and J. Y. Chen, 2006: Overview of ChinaFLUX and evaluation of its eddy covariance measurement. Agric. For. Meteor., 137, 125-137.

Zhang, H., A. Henderson-Sellers, A. Pitman, J. L. McGregor, C. E. Desborough, and J. Katzfey, 2001: Limited-area model sensitivity to the complexity of representation of the land-surface energy balance. $J$. Climate, 14, 3965-3986.

Zhang, X., F. W. Zwiers, G. C. Hegerl, F. H. Lambert, N. P. Gillett, and S. Solomon, 2007: Detection of human influence on 20th century precipitation trends. Nature, 448, 461-465. 